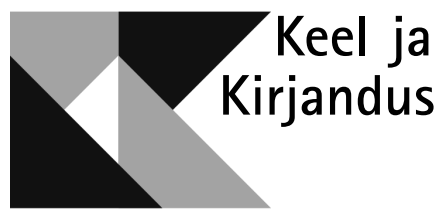

\title{
MARIE UNDER - JURI ŽIVAGO LUULETUSTE EESTINDAJA
}

\author{
IRINA BELOBROVTSEVA
}

$\mathrm{K}$

äesolev artikkel ${ }^{1}$ on pühendatud Boris Pasternaki Nobeli preemia (1957) pälvinud romaani „Doktor Živago” viimase peatüki tõlkele. Romaani peatüki nimetas Pasternak vastavalt „Juri Živago luuletused”, millega romaani autor „kinkis” oma teose nimitegelasele vaat et oma luule paremiku.

„Juri Živago luuletuste” tõlkimisloost on teada, et kõige rohkem on neid tõlgitud inglise keelde. Christopher Barnes, kes on kirjutanud neist vahendustest põhjaliku artikli, kus on kirjeldatud tõlkijate pidevaid ebaõnnestumisi, on ka ise proovinud õnne „Juri Živago luuletuste” tõlkijana. Tema arvates on Pasternaki luule „oma inglise tõlkijate ponnistuste suhtes õrritavalt tõrjuv. [Tema] stiili puhtus ja lihtsus tekitavad nii vähe tehnilisi probleeme, et tulemuseks võib kergesti olla banaalsus ja lamedus" (Barnes 2004).

Paljud esimestest Pasternaki romaani tõlkijatest eelistasid tõlkida „Juri Živago luuletusi” poeetilises proosas. Nii juhtus saksa, poola, läti, heebrea jpt tõlgetega. Luuletuste eestindaja valis aga raskema tee. „Doktor Živago” üllitati eesti keeles üsna kiiresti pärast Nobeli preemia pälvimist. Arusaadav, et mitte Nõukogude Eestis, kus see oli tollal võimatu, vaid Rootsis. Tõlge oli valmis 1959. aasta novembris ning trükivalgust nägi see 1960. aasta keskpaiku. Romaani proosaosa tõlkis Artur Adson, luule - Marie Under.

\footnotetext{
${ }^{1}$ Artikli autor tänab osutatud abi eest Rutt Hinrikust, Kalle Kurge ja Aurika Meimret.
} 
Asudes romaani tõlkima, kirjutas Adson 25. mail 1959 oma päevikus: „Neil päevil hakkasin tõlkima Dr. Živagot. Tükk aega kõhklesin, kas maksab? On see ju suur raamat ja esimene tõlge vene keelest paguluses. Kergesti samastatakse venelasi kommunistidega, kuigi Dr. Živago just läbiselt neile vaenuline on. Aga Vaba Eesti riskib." (Rootsipäevikud: 205) Fikseeritud on ka tõlke valmimise kuupäev: 28. november 1959.

Hämmastav on see, kuidas romaan „Doktor Živago” suutis kumuleerida skandaale. Alustades Nõukogude Liidu reaktsioonist Pasternakile Nobeli preemia andmise puhul: autorit sunniti preemiast loobuma - mida kirjanik ka tegi, et mitte kaotada Nõukogude kodakondsust (mis oleks tähendanud Venemaalt lahkumist). Skandaal puhkes ka eesti tõlke ilmumisel. Oma roll oli siin muidugi väliseestlaste üheselt negatiivsel suhtumisel kõigesse, mis oli seotud nõukogude võimuga. Ehkki Pasternaki tagakiusamine Nõukogude Liidus oleks võinud teha temast automaatselt totalitaarse võimu märtri, ei näinud eesti pagulased asju nii lihtsalt. Adson kirjeldab oma päevikus 18. veebruaril 1960. aastal kirjastuste Orto ja Vaba Eesti vahelist konflikti: „Dr. Živago ... on tekitanud terava poleemika. Seda teost kavatses Orto välja anda, trükkides ära oma lehes 5. nov. 1958. a. päris pika artikli, milles on öeldud, et teoses kritiseeritakse kommunistlikku korda, et autor langevat nüüd lõpliku põlu alla ja võib saada saadetud Siberisse. Sama lehe följetonis nimetati Pasternaki romaani „dünamiidipadruniks Kremli bosside istme all”. Tõlkijaks pidi olema üks daam, kes varem kunagi kirjanduses esinenud ei ole. Kuuldes sellest ja kartes pääliskaudset tõlget sellele väärtteosele, otsustasime lõpetada kõhklemise ja tegima (sic! - I. B.) Vaba Eestiga lepingu, et tõlgime meie." (Rootsipäevikud: 216)

Adson põhjendas päevikus oma sobivust kuulsa romaani eestindamiseks sellega, et omal ajal sai ta kirjanduskonkursil auhinna Nikolai Gogoli tõlkijate jaoks keeruka teose „Tarass Bulba” tõlkimise eest. Teda (ja suure tõenäosusega ka Underit) pani eriliselt muretsema mõte sellest, kuidas kulgeb dr Živago värsside eestindamine debütant-ümberpanija käes. Siit ka kirjanikepaari kindel otsus: „teeme selle ümberpaneku ise kõige oma oskuse ja süümega. Under luule, mina proosa. Kirjastus Vaba Eesti hankis enesele kohe Itaaliast Feltrinelli kirjastuselt ainuõiguse eestikeelse tõlke tarvis ja teatas sellest avalikult lehes. Nüüd alles Orto omaniku süda kihvatas: kuidas julgeb üks ideeline noor kirjastus tema loodetava äri nurja ajada! Ja lavastas lugejate vahel ringküsimuse Dr. Živago soovitatavuse kohta eesti keeles. Varem on Orto küllalt tõlkeid avaldanud, ilma lugejailt nõu küsimata. Nüüd Dr. Živago puhul „saavutas" ta siis lugejate eitava otsuse nagu teatas oma kirjastuse bülletäänis, mis koos ühe kuuraamatuga lugejaile laiali saadeti. [---] Kena küll, kui kirjastaja tarkust turult läheb otsima... Selle päästva õlekõrre järele haaramisega ei suutnud ta aga varjata asjaolu, et kui Orto Dr. Živagot asus välja andma, siis ei olnud see kommunistliku propaganda teos, kui aga väljaandjaks sai teine kirjastus, siis muutus romaan kohe „Moskva käsilase" teoseks." (Rootsipäevikud: 217)

Adson hindas romaani väga kõrgelt. Kuna tema ja Underi arvamused kirjanduse osas langesid tol ajal peaaegu alati kokku, siis võib arvata, et Adsoni päevik peegeldab ka Underi suhtumist „Doktor Živagosse”. 25. veebruaril 1960, teose ilmumisel, kirjutas ta: „Tõeline elamus oli mul seda tõlkida. Olen kõigi lugemiste, revisjonide, korrektuuride ja lõpuks valmis eks. veelkordse lugemisega (et trükivigu parandada) kokku seda teost seitse korda lugenud. 
[---] Kogu muu Pasternaki proosa, mille ta nooremana on kirjutanud, ei ulatu kaugeltki Živago tasemeni. Ja oma nooreea luuletuste kohta on ta ise ütelnud, et kaht kolmandikku neist ta enam ei tunnusta. Selle vastu Dr. Živago ja selle lõpus leiduva[d] luuletused on esmaklassilised. See on romaan, milliseid vähe sellise südamerakendamisega on kirjutatud, ja ta armastuse kirjeldamised ning läbielamised on nii haaravad nagu seda nüüdsel ajal üldse enam ei kirjutata. Vahest minevikust võttes Hamsuni Viktoorial on sama väärtus. Pasternaki looduskirjeldused ja kogu Siberi episoodistik on suure kunstniku loodud. [---] Nobeli laureaatidest on ta kõrgemal kui Eliot, Faulkner, Hesse, Lagerkvist, Jensen, Russe[ll], eriti aga Churchillist... Ometi kord Nobeli-määrajad tabasid ka märki." (Rootsipäevikud: 232-233)

1958. aasta lõpus, veel enne Živago luuletuste tõlkimisega alustamist, teatas Under Ivar Ivaskile: „Vahepääl olen lugenud läbi „Dr Živago”, mis mind väga-väga haaras. Kompositsioonilised nõrkused, mis talle mõnelt poolt siin ja nagu Stockilt kuulen, ka saksa arvustuste poolt ette heidetakse, ei häiri mind sugugi. Mõni teos võib olla kompositsiooniliselt kõige täiuslikum, kuid jätab oma vaimu ja hingejõu poolest täiesti külmaks. Ja need luuletused raamatu lõpus on omas lihtsuses ütlemata kaunid.” (Under Ivaskile 28. XI 1958, 1 39/63)

Ent see luuletuste lühiiseloomustus ei peaks lugejat petma: lihtsuse all ei peeta siin silmas arusaamise hõlpsust, vaid luuleteksti terviklikkust ja tähenduse mahutatavust. Tõlkimise käigus põrkus Under paljude raskustega. Teatavat osa neist põhjendab ta eelkõige vene ja eesti keele erinevusega, kõige sagedamini aga eesti keele riimivaesusega võrreldes vene keelega. Sellest kirjutab ta ka oma korrespondentidele.

„Doktor Živago” tõlkimisega olid seotud kaks eesti päritolu USA professorit ning üks teadur: Florida ülikooli professor Ants Oras ja Oklahoma ülikooli professor, hiljem, alates 1967. aastast ajakirja World Literature Today peatoimetaja Ivar Ivask. Teadurist - pisut hiljem.

Ants Oras sai Adsoni ja Underi kavatsusest tõlkida „Doktor Živagot” teada hulk aega enne seda, kui nad oma tööga alustasid. Oras kirjutab Ivar Ivaskile (4. XI 1958): „Kas Adson ja Under oskavad Pasternaki mõjuvalt tõlkida? Kahtlen selles natuke. Adsoni keel on lamedavõitu, ja Under ei ole enam Under, kui ta tõlgib. (Nagu muide ka Pasternak lööb peaaegu alati originaalist mööda, kui hakkab tõlkijaks: kirjutab hiilgavaid värsse, kuid need on pärit hoopis teistsugusest maailmast kui algupärandid).” (Akadeemia kirjades 1997: 79)

Sel ajal peab Ivask aktiivset kirjavahetust Underiga, aidates poetessi tõlkimisel. Ta loeb Underi tõlkeid mitmeid kordi üle, lisab neile märkusi, põhjendab oma arvamusi. Under omakorda kasutab tema abi, tunnistab Ivaski maitset ja takti, peab temaga nõu tõlkeprobleemide üle. Ivask hindab Underi Pasternaki luule tõlget väga kõrgelt ja kui ta milleski kahtleb, siis ainult romaani proosaosa tõlke kvaliteedis. Tundes Pasternakki isiklikult, kirjutab ta tema luulest artikli Manasse, mis ilmub Underi kolme Juri Živago luuletuse tõlke eessõnana (Ivask 1959).

Artikliga seonduvalt toonitab Oras taas kord kirjavahetuskaaslasele oma nõudmisi tõlkele: tõlkija peab kohusetruult järgima algupärandit ja sellega ka piirduma. Ta kritiseerib Underit eelkõige irdriimide kasutamise pärast: „Teie artikkel on üsna tore, kuid Underi tõlkeid ma ei saa nautida. Ta ei saa enesest välja, ja pealegi teeb ta endale ülesande ka väliselt kergeks, kasutades kohmakaid irdriime. Kõige vastumeelsemad viimastest on minule need, kus rõhutud vokaalid erinevad („tulge” - „sulgi” tüüp). [---] Adams kasutas neid 
tihti, ilmsesti vene keele mõjul, kus rõhuta vokaalide hääldamine ebamäärastub. Eesti keeles neid hääldatakse väga selgesti, nagu üldse on meie lõppvariatsioonidega keel just sõnalõppude suhtes eriti tundlik. Sellest Under pole aru saand. Originaalluules juhivad teda vaist ja inspiratsioon, kuid tõlgetes ta näib toimivat mehhaanilisemalt...." (Akadeemia kirjades 1997: 122)

Ants Oras omakorda hakkab ka ise Pasternaki luulet inglise keelde tõlkima, järgides omaenda meetodit. Samas kaugeneb ta autori „teenri” rollist oluliselt. Ta suisa „puhastab” teda ärritavad Pasternaki irdriimid oma tõlkest välja. Orase uurija Anne Lange märgib: „Orase riimid on tõlkes puhtamad kui originaalil. Ta ise möönab, et riimide foneetilist täpsust taga ajades ujub ta vastuvoolu kaasaegsele angloameerika tõlketavale irdriimida.... Oras ütleb, et on vanamoodsaid puhtaid riime kasutanud oskamatusest leida irdseid, mis oleksid niisama efektsed ja veenvad kui Pasternakil. Talle on jäänud väheks quasi-riimidest, mis ehk organiseerivad küll rütmi, aga ei näita kätte ridade seotust ega too välja luuletuse stroofistruktuuri." (Lange 2004: 234)

Täiesti vastupidine oli luuletaja, kriitiku ja tõlkija Aleksis Ranniti (sündinud Aleksei Dolgošev), toonase Yale’i ülikooli vanemteaduri ning slaavi ja idaeuroopa kollektsioonide kuraatori arvamus. Erinevalt Orasest arvas Rannit, et hea, täiesti hea tõlge p e ab võistlema algupärandiga. Oma arvustuses eestikeelsele „Doktor Živagole” Tulimullas kirjutas Rannit, et tegu on „eesti loova sõna meistriteosega” ja et „[e]estlased võivad sellele tõlkele uhked olla" (Rannit 1962: 221). Seejuures võrdleb ta eestikeelset vahendust kõigepealt prantsuse ja saksa tõlgetega, mis on tema arvates ebaõnnestunud, seejärel aga ka inglise-, itaalia-, poola-, ukraina-, tšehhi-, leedu- ja soomekeelsete tõlgetega, järeldades: „Ka need on nõrgad...” (Rannit 1962: 217). Rannit omakorda on püüdnud aidata Underit Pasternaki mõistmisel. Näeme seda poetessi kirjast Ivar Ivaskile: „Rannit saatis ka meile oma P[asternaki] rütmi analüüsi. ${ }^{2}$ Näib, et ta on põhjalikult süvenend kõigisse P[asternaki] stilistilistesse võtteisse ja detailidesse. [---] Ranniti saadetisest selgub, et ta on juba Eestis tegelend P[asternaki] luulega ja kirjutand sellest „Kaunis Kodus”.” (Under Ivaskile 17. XII 1959)

Marie Underi tõlge ei ole ideaalne, kuid käesoleva artikli autori arvates ei ole mõtet pöörata tähelepanu tõlkija üksikutele eksimustele. Kas üldse on olemas ideaalseid tõlkeid? Märksa huvitavamana tunduvad mulle ühest küljest need raskused, mis ootasid „Juri Živago luuletuste” eestindajat, teisalt aga tema strateegilised otsused, mis tunduvad igati huviäratavatena ning aitavad mõista Underi kui tõlkija peamisi põhimõtteid. Tema lähenemine tõlkele kattub kontseptuaalse analüüsi põhjal tehtud samaväärse tõlke reeglitega, kus tunnistatakse tõlkija õigust autori mõtte ja võtmemõistete säilitamisele, kuigi need võivad tekstifragmendi suhtes olla ka teisenenud. Samaväärsuse (ingl concept equivalence) mõistet on seletatud järgmiselt: „Mõnes keeles võib mõistet esitada mitte ainult sõna või sõnadega, vaid ka morfeemi, idiomaatilise väljendi, mõne tooni või sõnajärjestusega. [---] Ühes keeles võivad mitu erinevat mõistet olla edasi antud ühe sõnaga, mis aga teise keelde võidakse tõlkida ühe-kahe sõna, väljendi või isegi terve lausena. Seda nimetatakse mõiste samaväärsuseks.” ${ }^{3}$

${ }^{2}$ Siin on kõne all artikkel Rannit 1959, 1960.

${ }^{3}$ Vt selle kohta nt: Li, Yang 2006: 632-644; Laurence, Margolis 2003: 253-282; Block, Stalnaker 1999: 1-46. Kontsepti kui kultuuri baasühiku kohta vt Stepanov 1997. 
Ehkki 1950. aastate lõpus, kui Under tõlkis „Juri Živago luuletusi”, kontseptuaalse analüüsi mõistet tõlgete puhul veel ei kasutatud, leiame me selle selgeid jooni tema tõlkes. Võib-olla on selle kõige drastilisem näide peidetud luuleteksti dekompressiooni kasutamisse. Kuna Underile tehti etteheiteid irdriimide rohke kasutamise pärast, lisab ta esimese tsükli luuletuse juurde enneolematu viite: „Järgnevate luuletuste originaalis on ohtrasti kasutatud irdriime, vastavalt on ka tõlkija toiminud" (Pasternak 1960: 503).

Under luges originaali ülimalt tähelepanelikult, järgides teksti vaimu, mitte kirjatähte. Seda tõendab kas või selline, lugejatele võib-olla vaevu märgatav fakt, et ta ei korranud Pasternaki nn autorikurtuse ${ }^{4}$ kaasust, mis tekkis luuletuses „Pulmad”, kus üht ja sama pilli nimetatakse kord lõõtspilliks, kord akordioniks.

Tõlkimise käigus tekivad Marie Underil tekstist omaenda versioonid ja seda mitte harva. Mõne näite põhjal selgitan, kuidas tõlkija loob omamoodi dialoogis algupärandiga oma teose või teose fragmendi kontseptsiooni, ületades originaali ja tõlke keelte ning ka muid erinevusi. Selles kontekstis on selge, et erinevused originaalist, mis märgatavalt tõusevad esile Underi tõlkes, on iga kord põhjaliku kaalutlemise tulemus.

\section{Piibli konnotatsioonid}

„Juri Živago luuletused” võib tingimisi jaotada kaheks: piibliainelised ja ilmalikud luuletused. Under usaldas tõlkimisel ilmselt oma mälu ega värskendanud seda ei Vana ega Uue Testamendi ülelugemisega. Siit tuleneb mõnikord ekslik, kaanonile mittevastav nimetus, nt kast kanoonilise laeka asemel või siis leinakate surilina asemel. Suure algustähe, mida sügavalt religioosne Pasternak on kasutanud selliste sõnade nagu Jumal (koos tema erinevate nimetustega), Jumalaema, Ülestõusmine puhul, on Marie Under sageli asendanud väikese algustähega. Sellegipoolest saab ta aru, et Pasternaki tekstid on täis piibliassotsiatsioone, mistõttu on ta neid kasutanud ka ilmalikes luuletustes. Näiteks värsiread

И так с привязанностью слуг

Весь век благоговею ${ }^{5}$

on Under tõlkinud järgmiselt:

Nii hardaks teeb see ime, et ma palvetusse paelun.

Nii saavutab tõlkija piibliteemalise ja ilmaliku luule tasandite võrdsustamise.

Mis aga juhtub siis, kui me ei pööra piibli konnotatsioonidele kohast tähelepanu? Selle tunnistuseks on dramaatiline möödalugemine, mis on toimunud

${ }^{4}$ Termin (vn авторская глухота), mille vene kirjandusteaduses võttis kasutusele Maksim Gorki ja millega tähistatakse mitmesugeid kirjandusteostes esinevaid vigu, mida autor ei ole tähele pannud.

${ }^{5}$ Reaaluses tõlkes: „Niigi teenrite kiindumusega / kogu eluaeg aukartust tunnen.” Tegu on luuletusega „Avaldus” („Объяснение”). 
luuletuse „Koidikul” („Рассвет”) tõlkimisel. Vene ja eesti keele erinevuste tõttu kaob evangeeliumi alltekst tõlkes hoopis ära. Kuna eesti keeles puudub soo grammatiline kategooria, saame sellest luuletusest aru kui lüürilise minategelase pöördumisest naise poole. Originaalis on see adresseeritud Kristusele:

Ты значил все в моей судьбе [---]

Всю ночь читал я твой завет...
Sa olid minu elus kõik [---]

ma lugesin su läkitust...

Tõlkes jääb arusaamatuks, miks ühe naisterahva läkitus põhjustab minategelase ühinemise teiste inimestega ja kutsub esile tugeva empaatiatunde kõigi nende suhtes. Tundub, et siin pole tõlkija lõpuni aru saanud, millest on jutt. Probleem peitub sõnas завеm, mis on Underi tõlkes tavaline läkitus, sellal kui nii Vana kui ka Uue Testamendi tekstides tõlgitakse seda sõna eesti keelde järjepidevalt lepinguna (vt ka 1Ms 6: 18, 1Ms 9: 9, 3Ms 26: 15, Jr 32: 40 jpt).

Väga heaks näiteks selle kohta, et Under ei liigu luulekeelega ühes rütmis, vaid valib alateadlikult Pasternaki tõlgete juures kontseptuaalse põhimõtte, on nt luuletus „Jõulutäht” („Рождественская звезда”). See tundus talle ühtlasi ka kõige raskemini tõlgitava luuletusena. Just siin ei pööra ta tähelepanu Pasternaki jaoks olulisele komponendile - suurele algustähele - ja kirjutab originaalis suurtähelised sõnad Imik, Jumal, Jõulud väikese algustähega. Võimalik, et ta ei pea imikut jumalaks, vaid inimeseks. Millest selline oletus? Aga sellest, et Under lisab oma tõlkesse piibli konnotatsiooni - varjatud tsitaadi, mida Pasternakil ei ole! See on Pontius Pilatuse tuntud hüüatus „Ecce homo!” - eestikeelses evangeeliumis „Ennäe inimest!”, mille ta viib viimasesse, st rõhulisse salmi:

...Вдруг кто-то в потёмках, немного налево.

От яслей рукой отодвинул волхва, И тот оглянулся: с порога на Деву, Как гостья, смотрела звезда Рождества. ...äkki keegi sõime eest eemaldas targa, pannes külge tall' käe too vastas: ennäe! Kui külaline säält künniselt külmalt jõulutäht vaatas Neitsile silma.

Ja kuigi tõlge on üldiselt piisavalt täpne, ilmub siia võrreldes algupärandiga uus sõna ennäe!, mis moodustab pelgalt esimese osa sellest tuntud sõnaühendist, aga täiesti selge, et siinkohal on tegu piibli konnotatsiooniga.

Marie Underi püüd anda edasi Boriss Pasternaki luuletuste piiblimõisteid ei tähenda sõnasõnalist ja ridarealist tõlget. On juhtumeid, kus originaali kontsept langeb tõlkija loodud tähenduste võrku, mille kaudu luuletus omandab uue, täiendava mõtte. Lugeja ei pruugi kohe esimese sellise juhtumi puhul seda täiendust ära tundagi ega mõista tehtava tähtsust. Kõigest sellest saab ta aru lugemise edenedes. Võtame näiteks nihutatud tähenduslikud rõhud luuletuse „Pahad päevad” („Дурные дни”) tõlkes:

И сборище бедных в лачуге, И спуск со свечою в подвал, Где вдруг она гасла в испуге, Когда воскрешённый вставал.
Ja vaeste kogumist hütis ja küünlaga koopasse käik, kuis kui surnu ellu sääl süttis, kustus kohkudes küünla läik. 
Kahe viimase värsirea ümbertõstmine ei ole minu nägemust mööda riimile või rütmile lõivu maksmine (ehkki, nagu eespool öeldud, just sellega õigustab Under oma tõlkevalikuid Ivar Ivaski ees). Arvata võib, et eestindaja tunnetas siin küünlaleeki kui romaani üht peamist sümbolkujundit - põlevat küünalt. Selles oli tal muidugi õigus. Ent antud juhul avaldus just värsiridade vahetamises Pasternaki ja Underi sümbolkujundite hierarhia võtmeerinevus. Pasternaki jaoks on ülestõusmine (nagu ka elluärkamine) tahte kõrgeim pingutus ja kõige olulisem püha, kõige kõrgema eesmärgi saavutamine. ${ }^{6}$ Pasternak rõhutab eriliselt surnust üles tõusvat Laatsarust, sellal kui Under jääb näiliselt truuks esteetilistele kaanonitele. Samas omandab see kujund teise, religioossusele kauge tähenduse, selgitades kogu luuletsükli vältel, kuivõrd tähtis on tõlkija valitud strateegia.

\section{Tõlke soolised eripärad}

Analüüsides Marie Underi „Juri Živago luuletuste” tõlke strateegilisi otsuseid, peab kindlasti arvestama ka soolise alge tähtsust. Nagu iga tõlkija, nii oli ka Under omaenda vaimsuse nimel vahetevahel sunnitud eemalduma algupärandi kirjatähest. Siinkohal viitan kahele näitele, kus ta näitab ennast tõelise naisena, stabiilsuse ja tasakaalukuse kehastusena.

Tegu on luuletusega „Talveöö” („Зимняя ночь”), kus vastandatakse välist ja sisemist ruumi. Vene kirjanduse traditsioonile omase lumetormi kui kõikvõimsa stiihia vastasseisu haprale inimlikule algele lahendab Pasternak nii selles kui mõnes teiseski Juri Živago luuletuses stiihia ja inimese võrdsustamise kaudu. Kirjandusteadlaste arvates rõhutatakse siin konkreetset aega tegelase elus: konkreetne kuu, veebruar, mil nimitegelase elu sai sümboolse tähenduse. Selles luuletuses olevikku nagu ei olegi. Kõik toimub minevikus (vt selle kohta Kozlov, Mirošnitšenko 2012: 26-27). Täpselt nii tõlkis 1966. aastal selle luuletuse eesti keelde ka Uno Laht, kelle tõlkes on olemas ka vastav refrään:

Jäänd küünal laual põlema

ja küünal põles. ${ }^{7}$

Ent Underi tõlkes on erinevalt originaalist olevik olemas ning taas mängib ta küünlaga:

Jäänd küünal laual põlema

ja küünal põleb.

Võib öelda, et Underi strateegilise otsuse tulemusena ei sümboliseeri see luuletus enam konkreetset perioodi tegelaskuju elus, vaid armastuse

${ }^{6}$ Vt ka luuletust „Vaiksel nädalal” („На Страстной”): „... võib ülestõusmisjõud ja hoog / tõest ära võita surma" (...Смерть можно будет побороть / Усильем Воскресенья). Vt selle kohta ka: Bodin 1976: 11.

${ }^{7}$ Algupärandis kordub refrään „Свеча горела на столе, / Свеча горела” muutmata kujul neli korda. Uno Lahe riimiotsingud selle luuletuse tõlkes sundisid teda refrääni muutma, säilitades selle vaid kaks korda: „Mu laual küünal põles truult, / mu küünal põles”; „Mu küünal põles keset ööd, / mu küünal põles” ja viimaseks, algupärandile kõige omasemal kujul: „Mu küünal põles laua peal, / mu küünal põles” (Pasternak 1966). 
võidukäiku stiihia üle, mille kaudu on armastusest saanud osaline olevikus, igavikus ja surematuses. Just otsus igavese (sest küünal ei kustu luuletuses kunagi) armastuse kasuks on see, mis tundub uurijale puhtnaiseliku võttena.

Teine soolise faktori näide on luuletuse „Kohtumine” (Свидание”) tõlkes. Tegu on kahe värsireaga: „И каплями росинки / Сверкают в волосах”. ${ }^{8}$ Kaine mõistus ütleb, et kaste ja kastetilgad ning lumi ei saa looduses olla samal ajal. Ent Under, kes mõistab, et Pasternaki tegelaskuju lähteks on võrdlus, leiab sellele puhtnaiseliku vaste. Ta rajab silla ühest kunstiliigist teiseni, panustades lugeja, maalikunsti austaja, visuaalsele mälule. Just sealt, renessansi ajastu kunstnike naiseportreede seast leiab Under reaalia, mis antud kontekstis täidab võrdluse funktsiooni: sätendav, st kuldne või hõbedane või ka kalliskividega juuksevõrk. Tema tõlke vastavad read näevad välja sellisena:

...ja kastepiiske võrgust

su juuksed särastet.

\section{Keelte erinevusi}

Tõlketöös esinevaid raskusi arutab Marie Under kirjavahetuses Ivar Ivaskiga, kusjuures ta arvestab viimase märkustega ja loob üha uusi variante. Pidevalt õigustab ta irdriimide sagedast kasutamist. „Oo, jah, need riimid,” kirjutab ta, „aga Te teate ju, et need P[asternaki] juures teadlikult ja tahtlikult pole alati puhtad - jah, vahel päris „barbaarsed”. Kui vene keele riimirikkus pole ahvatlend autorit täiel määral kasutama, vaid vastupidi oma jagu hülgama, siis, armas kuri kriitik, palun väga... Kui rikas riimi-keel seda teeb, siis oleks ülearune rangus seda meie keelele pahaks panna." (Under Ivaskile 7. XII 1959)

Luuletuse „Vaiksel nädalal” („На Страстной”) puhul ta ei näe võimalust eesti keelde ümber panna kümmet riimilist kordust ja seda kahe salmi kestel, milliseid originaalis on koguni üksteist: „Siia pean ma lisaks veel ikka jälle oma vana märkuse poetama, et eesti keel on riimivaene. Kui ikka riimi-tagavaraga keeltesse tõlkijad nagu sakslane, prantslased, rootslased pole toime tulnud riimides tõlkimisega, siis tohiks küll vist riimides tõlkimist eesti keeles enam-vähem saavutuseks pidada.” (Under Ivaskile 7. XII 1959)

Saates Ivar Ivaskile järjekordses kirjas luuletuse „Humal” („Хмель”) tõlke, märgib Under, et "Ss-sisinat ${ }^{9}$ oli võimatu saavutada: on ju ikkagi tegemist kahe täiesti erineva keelega. Peab ju loomulikult edasi andma seda, mida autor on tahtnud ütelda - see dikteerib ju ka võimalused" (Under Ivaskile 7. XII 1959).

Under püüab mingil määral kompenseerida algupärandis oleva 12 sisiseva hääliku alliteratsiooni assonantsi ( $24 a$ ja $24 e$ abil) ja $15 m$-i alliteratsiooniga. Võib eeldada, et ta teeb seda mitte ainult kompensatoorsel eesmärgil. Underi horisont on laiem: kontekstuaalsete konnotatsioonide tõttu toimub siin tema valitud häälte semantiseerimine. Asi on selles, et Živago luuletus „Humal” on

\footnotetext{
${ }^{8}$ Reaalune tõlge: „Ja kastepiisad tilkadena / sätendavad juustes.”

${ }^{9}$ Marie Under mõtleb siinkohal alliteratsiooni: Под ракитой, обвитой плюЩом, / От ненастья мы иЩем заЩиты. / НаШи плеЧи покрыты плаЩом, / Вкруг тебя мои руки обвиты. // Я оШибся. Кусты этих чаЩ / Не плюЩом перевиты, а хмелем. / Ну, так лучШе давай этот плаЩ / В Ширину под собою расстелем (suurte tähtedega on märgitud alliteratsioonis osalevad tähed).
} 
paigutatud pärast luuletust „Tuul” („Ветер”). Viimase tõlkes aga näeme tuule hällilaulu onomatopöad, kus korduvad häälikud $a, m, u$ ja $n$. Seega kordab „Humal” foneetilisel tasemel inimese liitumist loodusega või koguni inimese looduses lahustatuse teemat. Ja seda kõike tänu armastusele, millist Marie Under kahtlemata tunnetas Juri Živago luuletuste juhtmotiivina.

Ent vaatamata kurtmisele kahe luulekeele erinevuste üle, loob Under oskuslikult ka luuletuse „Sügis” („Осень”) tõlkes märgilise onomatopöa. „Ss-sisina” asemel, mis pidi assotsieeruma lehesajuga, valib ta jälle assonantse sügisese tuule undamise:

ЕЩе пыШней и бесШабаШней Шумите, оСыпайтеСь лиСтья

И ЧаШу гореЧи вЧераШней

СегодняШней тоСкой превыСьте.
Veel hUnnitumalt koha pUUdes, tUUl, Uljamalt sa mÜha aiva! Ja eilse kibedUse krUUsi veel jUUrde lisa tänast vaeva.

Tõlkija valik - asendada assonants alliteratsiooniga - muudab luuletuse foneetilise tasandi teatud mõttes sarnaseks orkestreeringuga muusikas ning võimaldab lugejal seostada selle veel ühe assonantsiga. Nimelt on assonants osaline Juri Živago luuletuses „Tuul” nii originaalis kui ka Underi tõlkelises versioonis. ${ }^{10}$ Sellega tabas Marie Under eksimatult ära veel ühe Boris Pasternaki märkimisväärse luulekontsepti, milleks on „ühtne motiiv, üks tähtsamaid P[asternaki] maailmas". Pasternaki luule uurija Aleksandr Žolkovski vägagi õiglase vaatluse kohaselt ei saa „Juri Živago luuletuste" tu ule motiivis „välistada (eriti tsükli kristliku temaatika valguses) ka piibli intertekste, nt Jh 3: 8 - Tuul puhub, kuhu ta tahab" (vt selle kohta Žolkovski i.a).

Antud artikkel ei ole Marie Underi Boris Pasternaki „Juri Živago luuletuste" tõlke täielik analüüs. Siinse kirjatööga sooviti näidata, mil moel eksisteerivad tõlkimisprotsessis koos autori ja tõlkija kontseptuaalsed süsteemid ning kuidas tõlke keel ja kultuur tingivad teatud tõlkelisi strateegiaid, tuues sellega luuletekstidesse mh uusi ja ka täiendavaid mõtteid või tähendusi.

Kirjutise valmimist on toetanud Euroopa Liit Euroopa Regionaalarengu Fondi kaudu (Eesti-uuringute tippkeskus), see on seotud Eesti Haridus- ja Teadusministeeriumi uurimisprojektiga IUT 18-4 „Eesti Ida ja Lääne vahel: „oma”, „teise”, „võ̃ra”, „vaenlase” kujundite paradigma XX sajandi Eesti kultuurides”.

\section{Arhiiviallikad}

Ad s o n, Artur. Rootsipäevikud. - KM EKLA, f 180, m 164.

Marie Underi kirjad Ivar Ivaskile. - KM EKLA, f 180, m 45.

\section{Kirjandus}

Akadeemia kirjades. Ants Orase ja Ivar Ivaski kirjavahetus 1957-1981. Koostanud ja kommenteerinud Sirje Olesk. Tartu: Eesti Kirjandusmuuseum, 1997.

${ }^{10}$ Seekord moodustavad assonantsi täishäälikute $u$ ja $a$ kordused, millised assotsieeruvad tuulepuhangutega, tuule ulgumisega: „Ma surin, sina ellu jäid. / Ja tuulehalin, nutukaja / on kõigutamas metsa, maja..." 
Barnes, Christopher 2004. Translating the Zhivago Cycle. - Boris Pasternak. Poems of Doctor Zhivago. - Toronto Slavic Quarterly, nr 10, Fall. http://www. utoronto. ca/tsq/10/barnes10.shtml

Block, Ned, Stalnaker, Robert 1999. Conceptual analysis, dualism and the explanatory gap. - Philosophical Review, nr 108.

Bodin, Per-Arne 1976. Nine Poems from Doktor Zivago. A Study of Christian Motifs in Boris Pasternak's Poetry. Stockholm.

Iva sk, Ivar 1959. Boris Pasternaki romaani ja luule suhteist. - Mana, nr 3, lk $155-162$.

Kozlov, Mirošnitšenko 2012 = Владимир Козлов, Оксана Мирошниченко, Жанровое мышление поэта Юрия Живаго. - Новый филологический вестник, nr 4.

La nge, Anne 2004. Ants Oras. (Eesti kirjanikke.) Tartu: Ilmamaa.

La u r en ce, Stephen, Margolis, Eric 2003. Concepts and conceptual analysis. Philosophy and Phenomenological Research, kd LXVII, nr 2, September.

Li, Kar Wing, Y a n g, Christopher C. 2006. Conceptual analysis of parallel corpus. - Journal of the American Society for Information Science and Technology, kd 57, nr 5, March. http://www.cis.drexel.edu/faculty/cyang/papers/yang2006c.pdf

P a s t e r n a k, Boriss 1960. Doktor Živago. Tlk Artur Adson ja Marie Under. Stockholm: Vaba Eesti.

P a stern ak, Boriss 1966. Talveöö. Tlk Uno Laht. - Looming, nr 11, lk 1719.

Rannit, Aleksis 1959, 1960. The Rhythm of Pasternak. - Bulletin of the New York Public Library, kd LXIII, LXIV.

R a n n it, Aleksis 1962. Eestindatud „Doktor Živago”. - Tulimuld, nr 3, lk 216-221.

Stepanov 1997 = Юрий Степанов, Константы. Словарь русской культуры. Опыт исследования. Москва.

Žolkovs ki = Александр Жолковский, Поэзия и грамматика пастернаковского „Ветра”. - http://www-bcf.usc.edu/ alik/rus/ess/bib401.htm

\section{Marie Under as the Estonian translator of „The Poems of Yuri Zhivago"}

Keywords: Marie Under, Boris Pasternak, Poems of Doctor Zhivago, poetics and strategies of translation

The present article is focused on the first Estonian translation of Doctor Zhivago's last chapter "The Poems of Yuri Zhivago". This translation was published in 1960 by the publishing house Vaba Maa in Stockholm shortly after Boris Pasternak was awarded the Nobel Prize in literature (1958). Artur Adson translated the prose, while "The Poems of Yuri Zhivago" were translated by Marie Under.

The article aims to reproduce a succession of some facts related to the translation process and the translation itself with the purpose of helping readers to appreciate this translation as a milestone in Estonian (and also Russian) literary history.

The analysis of the translation reconstructs the aged Under's understanding of Pasternak, i.e. the translator's concept of the cycle as a whole, its poems, and some components of the poems.

Irina Belobrovtseva (b. 1946), PhD, Tallinn University, School of Humanities, Professor of Russian Literature and Culture, venefil@tlu.ee 